\title{
Mortality in primary angioplasty patients starting antiplatelet therapy with prehospital prasugrel or clopidogrel: a I-year follow-up from the European MULTIPRAC Registry
}

\author{
This article was published in the following Dove Press journal: \\ Vascular Health and Risk Management \\ 19 April 2016 \\ Number of times this article has been viewed
}

\begin{abstract}
Patrick Goldstein'
Niccolò Grieco²

Hüseyin Ince ${ }^{3,4}$

Nicolas Danchin ${ }^{5}$

Yvonne Ramos ${ }^{6}$

Jochen Goedicke ${ }^{7}$

Peter Clemmensen ${ }^{8,9}$

On behalf of the MULTIPRAC study investigators

'Emergency Department, Lille Regional University Hospital, Lille, France; ' 2 Department of Cardiology, Hospital Niguarda Cà Granda Milano, Milan, Italy; ${ }^{3}$ Internal Medicine Centre, Cardiology Department, Rostock University Clinic, Rostock, Germany; ${ }^{4}$ Department of Cardiology, Vivantes Klinikum im Friedrichshain and Am Urban, Berlin, Germany; ${ }^{5}$ Department of Cardiology, European Hospital Georges-Pompidou, Paris, France; 'Medical Department, Daiichi Sankyo Europe, Munich, ${ }^{7}$ Medical Department, Lilly Deutschland $\mathrm{GmbH}$, Bad Homburg, Germany; ${ }^{8}$ Department of Medicine, Division of Cardiology, Rigshospitalet Copenhagen University Hospital, ${ }^{9}$ Department of Medicine, Division of Cardiology, Nykoebing F Hospital, Copenhagen, Denmark
\end{abstract}

Correspondence: Patrick Goldstein Emergency Department, Lille Regional University Hospital, Centre Hospitalier régional Universitaire de Lille,

2 Avenue Oscar Lambret,

59037 Lille, France

Tel +33 320444638

Fax +33 320444915

Email patrick.goldstein@chru-lille.fr
Aim: MULTIPRAC was designed to provide insights into the use and outcomes associated with prehospital initiation of antiplatelet therapy with either prasugrel or clopidogrel in the context of primary percutaneous coronary intervention. After a previous report on efficacy and safety outcomes during hospitalization, we report here the 1-year follow-up data, including cardiovascular (CV) mortality.

Methods and results: MULTIPRAC is a multinational, prospective registry of patients with ST-elevation myocardial infarction (STEMI) from 25 hospitals in nine countries, all of which had an established practice of prehospital start of dual antiplatelet therapy in place. The key outcome was $\mathrm{CV}$ death at 1 year. Among 2,036 patients followed-up through 1 year, 49 died (2.4\%), 10 during the initial hospitalization and 39 within 1 year after hospital discharge. The primary analysis was based on the $\mathrm{P} 2 \mathrm{Y}_{12}$-inhibitor, used from prehospital loading dose through hospital discharge. Prasugrel $(n=824)$ was more commonly used than clopidogrel $(n=425)$. The observed 1-year rates for $\mathrm{CV}$ death were $0.5 \%$ with prasugrel and $2.6 \%$ with clopidogrel. After adjustment for differences in baseline characteristics, treatment with prasugrel was associated with a significantly lower risk of CV death than treatment with clopidogrel (odds ratio 0.248; 95\% confidence interval 0.06-0.89).

Conclusion: In STEMI patients from routine practice undergoing primary angioplasty, who were able to start oral antiplatelet therapy prehospital, treatment with prasugrel as compared to clopidogrel was associated with a lower risk of CV death at 1-year follow-up.

Keywords: upstream treatment, $\mathrm{P}_{2} \mathrm{Y}_{12}$-inhibitor, dual antiplatelet therapy, primary percutaneous coronary intervention, observational

\section{Introduction}

A cornerstone of medication-based treatment of ST-segment elevation myocardial infarction (STEMI) is dual antiplatelet therapy (DAPT) with acetylic salicylic acid plus a P2 $Y_{12}$-inhibitor, in addition to anticoagulation. The P2 $\mathrm{Y}_{12}$-inhibitor should be administered at the time of first medical contact. ${ }^{1}$ The rationale for prehospital application of the loading dose (LD) is based on short period to primary percutaneous coronary intervention (PCI) in combination with pathophysiological alterations or co-medication with morphine, both known to cause delay in absorption/metabolization of orally administered drugs applied in the acute phase of STEMI. Accordingly, the onset of the antiplatelet effect of oral $\mathrm{P} 2 \mathrm{Y}_{12}$-inhibitors has been reported to be delayed in this setting, and this delay is more pronounced with clopidogrel ${ }^{2}$ than with prasugrel or ticagrelor. ${ }^{3}$ 
When looking at clopidogrel only, there is evidence from registries ${ }^{4,5}$ and from a meta-analysis of randomized clinical trials (RCTs) and registries ${ }^{6}$ that suggest that in STEMI patients, initiation of DAPT with clopidogrel before PCI treatment (primary PCI), compared with initiation at the time of PCI, is associated with lower mortality.

For the newer, faster acting and more potent $\mathrm{P} 2 \mathrm{Y}_{12}$-inhibitors prasugrel and ticagrelor, prehospital versus in-hospital initiation in the primary PCI setting has been formally tested in only one RCT with ticagrelor in both arms. The ATLANTIC trial, however, failed to show a benefit from prehospital initiation of ticagrelor when measured either by the two co-primary surrogate endpoints, or by mortality. ${ }^{\text {? }}$

It is less clear whether the benefit seen with early initiation of clopidogrel is of clinical relevance under today's clinical conditions, as prasugrel or ticagrelor should be the preferred treatment over clopidogrel, if not contraindicated. ${ }^{1}$

The European MULTIPRAC registry allows for a comparison between different $\mathrm{P} 2 \mathrm{Y}_{12}$-inhibitors in the setting of administration at first medical contact and with real-world treatment delays. After an earlier report of outcomes for the initial hospitalization, ${ }^{8}$ which showed modest and nonsignificant differences in clinical outcomes, here we report the 1-year follow-up data, including cardiovascular (CV) mortality.

\section{Methods}

\section{Design}

The design of the "MULTInational non-interventional study of patients with ST-segment elevation myocardial infarction treated with PRimary Angioplasty and Concomitant use of upstream antiplatelet therapy with prasugrel or clopidogrel (MULTIPRAC)" registry has been described in detail earlier. ${ }^{8}$ In brief, MULTIPRAC was a prospective noninterventional study, performed in compliance with the Declaration of Helsinki and local legislation. The primary ethics committee approval was obtained under the number 2011/141 by the Comité Etico de Investigacion, Clinica de Galicia Edificio Administrativo de San Lazaro, Santiago de Compostela (Spain), and further local ethics committee approvals were obtained. All patients provided written informed consent prior to documentation. The study has been registered in the German Clinical Trials Register (DRKS), an approved Primary Register in the World Health Organization (WHO) network (DRKS00003378).

Between June 2011 and June 2013, 25 PCI centers from nine countries, all of which had an established practice of prehospital treatment with one of the two $\mathrm{P} 2 \mathrm{Y}_{12}$-inhibitors available at the time the registry started, namely clopidogrel or prasugrel included consecutive patients arriving alive in the hospital catheterization laboratory. Their treatment was documented from symptom onset through hospital discharge, with a 1-year follow-up for vital status.

The enrollment criteria were age $\geq 18$ years, upstream thienopyridine LD (ie, $60 \mathrm{mg}$ prasugrel or $300 / 600 \mathrm{mg}$ clopidogrel) immediately after STEMI diagnosis and prior to/during ambulance transport to a catheterization laboratory hospital for primary PCI, written informed consent, and no enrollment in a competing clinical study.

At 1-year follow-up, the investigators were asked to report mortality only, an endpoint that can be collected at high rate of completeness, and which is inclusive of the most severe sequelae from re-infarction or bleeding occurring during follow-up. The source of information (eg, patient charts, physician, relatives, patient), death (yes, no, unknown) with date, and primary cause of death as indicated by the investigators ( $\mathrm{CV}$ death, non-CV death, and presumed $\mathrm{CV}$ death, defined as the composite of confirmed CV death and death not further specified) were collected. Follow-up was $99.2 \%$ complete.

The primary analysis of 1-year CV mortality from hospital admission through 1 year was based on the $\mathrm{P} 2 \mathrm{Y}_{12}$-inhibitor used from the prehospital LD until hospital discharge. This defined three groups of patients: a prasugrel group, a clopidogrel group, and a group of patients switched in-hospital from clopidogrel to prasugrel. The remaining 243 "other" patients were excluded from this analysis as they constituted a diverse group with complex switching patterns, even including switching to ticagrelor, at the end of the study period when this drug became available (Figure 1).

A secondary analysis grouped patients by the $\mathrm{P} 2 \mathrm{Y}_{12}$-inhibitor (prasugrel, clopidogrel, ticagrelor) prescribed at discharge, and deaths were considered between discharge and the 1-year followup. This sample included a smaller group of patients $(n=156)$ switched in-hospital to ticagrelor, mostly from clopidogrel. For these patients switched to ticagrelor and the 35 patients who had no $\mathrm{P} 2 \mathrm{Y}_{12}$-inhibitor prescribed at discharge, no statistical comparisons with the clopidogrel group were made, due to the small number of patients. Results are provided separately for $\mathrm{CV}$ death, all-cause death, and presumed CV death.

Continuous variables are reported as mean \pm standard deviation (SD) or medians with interquartile range. The main comparison was between prasugrel and clopidogrel groups, with $t$-test (when normally distributed) or the two-tailed MannWhitney $U$ test applied. Qualitative (binary or categorical) variables are reported as absolute and percentage numbers, and were compared by means of a logistic regression model. 


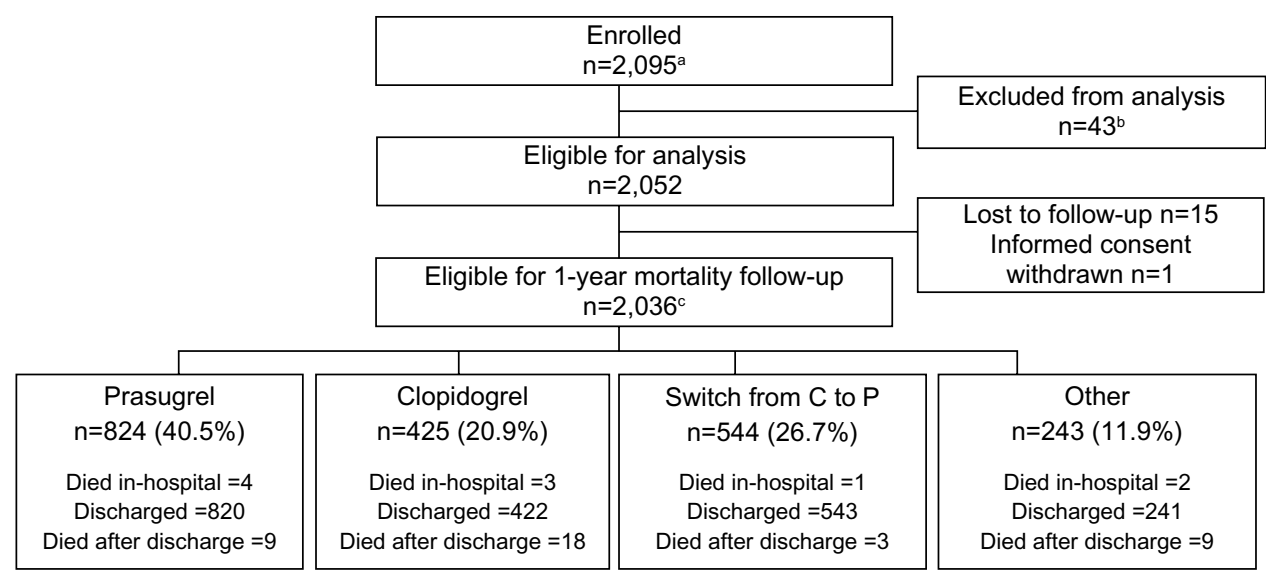

Figure I Patient flow and disposition.

Notes: ${ }^{2}$ Different from baseline data reported earlier, as one patient needed to be withdrawn (informed consent form was lost). 'Thirty-one missed loading dose, ten received loading dose in catheterization laboratory, one vomited after loading dose, one had no initial STEMI diagnosis. Includes ten patients who died in-hospital and 2,026 patients discharged from hospital with available I-year follow-up information.

Abbreviations: C, clopidogrel; P, prasugrel; STEMI, ST-elevation myocardial infarction.

Death rates in the various groups were compared with logistic regression models, as there was some uncertainty with regard to timing of death in a few cases. These models contained treatment as main effects, and were adjusted for differences between the treatment groups. The primary analysis was done on the basis of CV deaths; additional analyses were performed on all-cause and presumed $\mathrm{CV}$ deaths.

When adjusting for differences in baseline characteristics, the following covariates were used based on observed differences $(P<0.10)$ between prasugrel and clopidogrel groups: age (years), sex, center, time from symptom onset to start of PCI (minutes), glycoprotein inhibitor use prehospital and in-hospital, number of diseased vessels ( 0 or $1, \geq 2$ ), medical history of non-STEMI or STEMI, PCI, stroke, or transient ischemic attack (TIA), congestive heart failure, peripheral vascular disease, chronic renal impairment, and diabetes mellitus.

Results of all comparisons performed using logistic regression models are reported as odds ratio (OR) and 95\% confidence intervals (CIs), with $P$-values.

All statistical analyses were performed with SAS version 9.3 (SAS Institute Inc., Cary, NC, USA).

\section{Results}

\section{Pre- and in-hospital antiplatelet therapy}

Patient flow and disposition are displayed in Figure 1. Of the 2,036 patients eligible for this analysis, 927 (45.5\%) received prasugrel prehospital loading and 1,109 (54.5\%) received clopidogrel prehospital loading. Prehospital loading with clopidogrel was predominantly administered at the $600 \mathrm{mg}$ dose (84\%), and prasugrel loading was almost exclusively administered at the $60 \mathrm{mg}$ dose (99.5\%). A total of $15.7 \%$ of patients were on chronic acetylic salicylic acid with a median dose of $100 \mathrm{mg}$ and $2.7 \%$ were on chronic clopidogrel. Pre- and in-hospital administration of GPIIb/IIIa inhibitors was overall reported in $34.2 \%$ of patients, with a trend toward more frequent use in the prasugrel group versus the clopidogrel group $(35.7 \%$ vs $30.6 \%, P=0.072)$.

Reloading with a $\mathrm{P} 2 \mathrm{Y}_{12}$-inhibitor in the catheterization laboratory was more frequently done with prasugrel than with clopidogrel (20.2\% vs $2.3 \%)$. Before discharge, almost $20 \%$ of all patients were switched from one to another $\mathrm{P}_{2} \mathrm{Y}_{12}{ }^{-}$ inhibitor. The most frequent switching was from clopidogrel to prasugrel or to ticagrelor $(48.9 \%$ and $11.8 \%$ of those initially loaded with clopidogrel, respectively). Switching from prasugrel to one of the other $\mathrm{P} 2 \mathrm{Y}_{12}$-inhibitors was less frequent in prasugrel-loaded patients $(8.2 \%$ to clopidogrel and $2.8 \%$ to ticagrelor, for a total of $11.0 \%$ ).

The primary analysis was based on the $\mathrm{P} 2 \mathrm{Y}_{12}$-inhibitor used from prehospital LD until discharge from the hospital (prasugrel, $\mathrm{n}=824$; clopidogrel, $\mathrm{n}=425$; switched in-hospital from clopidogrel to prasugrel, $\mathrm{n}=544$ ).

\section{One-year follow-up}

The follow-up information was mainly extracted from patient charts (40.6\%) or obtained from the patient (38.4\%), and less frequently from a patient's relative $(11.6 \%)$ or the treating physician (8.7\%). Median time between PCI and the 1-year follow-up visit was 360 days (interquartile range: 343-375), with no difference between the prasugrel and clopidogrel groups (median, 360 vs 362 days). Of the 2,026 patients discharged from the hospital, a total of 1,344 (66.3\%) 
Table I Baseline characteristics, by $\mathrm{P}_{2} \mathrm{Y}_{12}$-inhibitor treatment from loading dose through hospital discharge

\begin{tabular}{|c|c|c|c|c|c|}
\hline Characteristic & $\begin{array}{l}\text { All patients, } \\
n=2,036 \\
(100.0 \%)\end{array}$ & $\begin{array}{l}\text { Prasugrel, } \\
n=824 \\
(40.5 \%)\end{array}$ & $\begin{array}{l}\text { Clopidogrel, } \\
\mathrm{n}=425 \\
(20.9 \%)\end{array}$ & $\begin{array}{l}\text { Switch from } \\
\text { clopidogrel to } \\
\text { prasugrel, } \\
\text { n=544 (26.7\%) }\end{array}$ & $\begin{array}{l}\text { P-value, } \\
\text { prasugrel vs } \\
\text { clopidogrel }\end{array}$ \\
\hline Age, years, mean (SD) & $60.8(12.1)$ & $57.1(10.1)$ & $66.9(13.3)$ & $58.3(10.2)$ & $<0.00 \mathrm{I}^{\mathrm{a}}$ \\
\hline Sex, female & $447(22.0)$ & I $40(\mid 7.0)$ & $139(32.7)$ & $99(18.2)$ & $<0.00 \mathrm{I}^{\mathrm{b}}$ \\
\hline Previous MI & $228(11.2)$ & $78(9.5)$ & $59(13.9)$ & $55(10.1)$ & $0.019^{\mathrm{b}}$ \\
\hline Congestive heart failure & $48(2.4)$ & $12(1.5)$ & $13(3.1)$ & II (2.0) & $0.06 \mathrm{I}^{\mathrm{b}}$ \\
\hline Previous $\mathrm{PCl}$ & $184(9.0)$ & $65(7.9)$ & $48(11.3)$ & $44(8.1)$ & $0.048^{b}$ \\
\hline Previous CABG & $29(1.4)$ & $8(1.0)$ & $9(2.1)$ & $4(0.7)$ & $0.106^{b}$ \\
\hline Previous stroke/TIA & $82(4.0)$ & II (I.3) & $33(7.8)$ & $5(0.9)$ & $<0.00 \mathrm{I}^{\mathrm{b}}$ \\
\hline Peripheral vascular disease & $80(3.9)$ & $21(2.5)$ & $26(6.1)$ & $10(1.8)$ & $0.002^{\mathrm{b}}$ \\
\hline Chronic renal impairment & $32(1.6)$ & $10(1.2)$ & $16(3.8)$ & $0(0.0)$ & $0.005^{\mathrm{b}}$ \\
\hline Diabetes mellitus & $275(13.5)$ & 94 (II.4) & $69(16.2)$ & $78(14.3)$ & $0.017^{\mathrm{b}}$ \\
\hline Killip class $\geq \mathbb{I I}^{c}$ & II $2(7.3)$ & $37(6.8 \%)$ & $30(9.7)$ & $29(5.9)$ & $0.133^{\mathrm{b}}$ \\
\hline $\begin{array}{l}\text { Time from SO to start of } \mathrm{PCl} \text {, } \\
\text { median (hh:mm) }\end{array}$ & $3: 15$ & $3: 12$ & $3: 30$ & $3: 00$ & $<0.00 \mathrm{I}^{\mathrm{d}}$ \\
\hline $\begin{array}{l}\text { Time from ISD to start of } \mathrm{PCl} \text {, } \\
\text { median (hh:mm) }\end{array}$ & $\mathrm{I}: 28$ & $1: 30$ & $\mathrm{I}: 32$ & $\mathrm{I}: 27$ & $0.116^{d}$ \\
\hline No of diseased vessels $(\geq 2)$ & $918(45.1)$ & $35 I(42.6)$ & $203(47.8)$ & $235(43.2)$ & $0.082^{\mathrm{b}}$ \\
\hline $\begin{array}{l}\text { Infarct-related artery: LMCA } \\
\text { or LAD }\end{array}$ & $884(43.4)$ & 352 (42.7) & $177(4 \mid .6)$ & $245(45.0)$ & $0.717^{b}$ \\
\hline
\end{tabular}

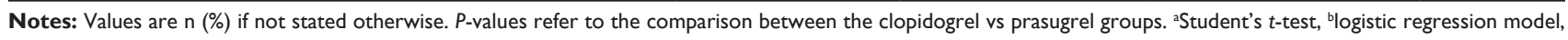
cinformation available from I,538 patients, and 'Wilcoxon signed rank test.

Abbreviations: CABG, coronary artery bypass graft; ISD, initial STEMI diagnosis; LAD, left anterior descending coronary artery; LMCA, left main coronary artery; MI, myocardial infarction; $\mathrm{PCl}$, percutaneous coronary intervention; SD, standard deviation; SO, symptom onset; TIA, transient ischemic attack.

were discharged on prasugrel, $491(24.2 \%)$ on clopidogrel, $156(7.7 \%)$ on ticagrelor, and $35(1.7 \%)$ without treatment with a $\mathrm{P} 2 \mathrm{Y}_{12}$-inhibitor.

\section{Demographic and clinical characteristics}

The baseline characteristics are presented in Table 1. Compared with patients on clopidogrel, those on prasugrel were substantially younger, more likely men, and less often had a history of stroke or TIAs. Further, patients on prasugrel less often had a history of myocardial infarction (MI) or PCI, peripheral vascular disease, congestive heart failure, chronic renal impairment, or diabetes mellitus. However, the number of diseased vessels as well as the distribution of infarct-related artery were similar (left main coronary artery and left anterior descending artery $42.7 \%$ vs $41.6 \%$ ), but time from symptom onset to PCI was 18 minutes shorter in the prasugrel group.

\section{Mortality at I-year follow-up}

In the primary analysis grouping patients by the $\mathrm{P} 2 \mathrm{Y}_{12^{-}}{ }^{-}$ inhibitor used from the prehospital LD until hospital discharge, a total of 49 deaths occurred, ten during the hospital stay and an additional 39 during follow-up. Twenty-two deaths were classified as $\mathrm{CV}$ death, 16 as non-CV death, and eleven were not further specified. The $\mathrm{CV}$ deaths occurred in four patients $(0.5 \%)$ on prasugrel, in eleven patients $(2.6 \%)$ on clopidogrel, in three patients $(0.6 \%)$ switched from clopidogrel to prasugrel (Figure 2), and in four patients $(1.6 \%)$ treated with other regimens ("other" group).

The adjusted OR for prasugrel patients compared with clopidogrel patients for CV death was $0.248,95 \%$ CI 0.069-0.893; for death from any cause OR $0.605,95 \%$ CI $0.263-1.391$; and for presumed CV death, OR $0.416,95 \%$ CI $0.155-1.115$.

For the group of patients who switched during the initial hospitalization from clopidogrel to prasugrel, compared with those who stayed on clopidogrel, the adjusted OR for CV death was 0.227 (95\% CI 0.050-1.038; Figure 3); for death from any cause OR 0.235 (95\% CI $0.065-0.847)$; and for presumed CV death OR 0.253 (95\% CI 0.068-0.939).

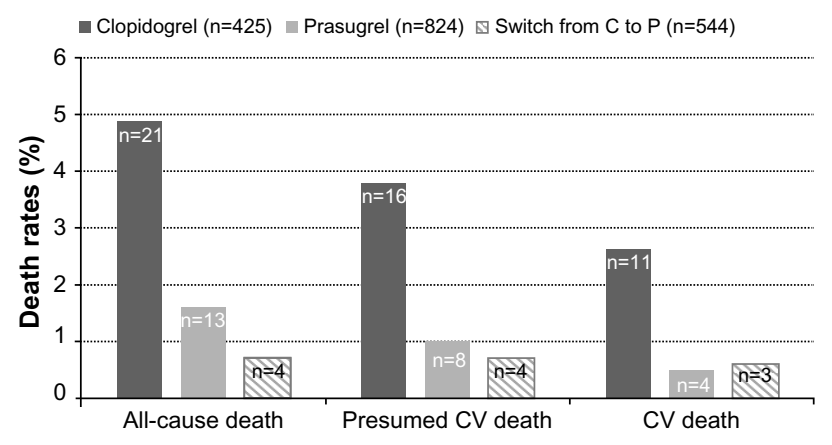

Figure 2 Death rates from hospital admission through I year.

Notes: Analysis is restricted to patients with documented I-year follow-up $(n=2,036)$. Abbreviations: C, clopidogrel; CV, cardiovascular; P, prasugrel. 


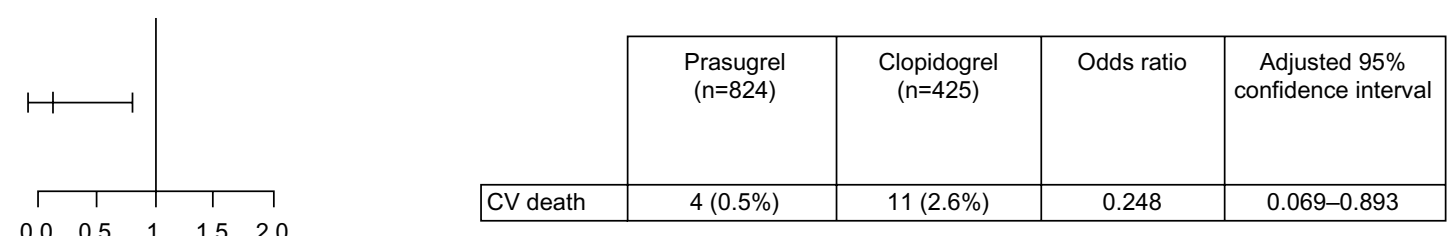

Favors prasugrel Favors clopidogrel

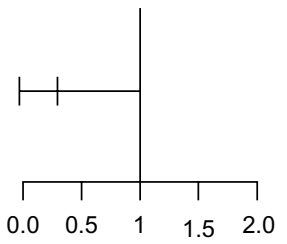

\begin{tabular}{|l|c|c|c|c|}
\cline { 2 - 5 } & $\begin{array}{c}\text { Switch from } \\
\text { clopidogrel to } \\
\text { prasugrel } \\
(\mathrm{n}=544)\end{array}$ & $\begin{array}{c}\text { Clopidogrel } \\
(\mathrm{n}=425)\end{array}$ & Odds ratio & $\begin{array}{c}\text { Adjusted } 95 \% \\
\text { confidence interval }\end{array}$ \\
\hline CV death & $3(0.6 \%)$ & $11(2.6 \%)$ & 0.227 & $0.050-1.038$ \\
\hline
\end{tabular}

\section{Favors prasugrel ${ }^{*} \quad$ Favors clopidogrel}

Figure $3 \mathrm{CV}$ death from hospital admission through I year by $\mathrm{P}_{2} \mathrm{Y}_{12}$-inhibitor treatment.

Notes: *Switched from clopidogrel. Confidence intervals were adjusted for differences in baseline characteristics. Data are based on linear regression model.

Abbreviation: CV, cardiovascular.

\section{Mortality analysis based on discharge medication}

This secondary analysis grouped patients by the $\mathrm{P} 2 \mathrm{Y}_{12^{-}}$ inhibitor prescribed at discharge, thus capturing only the 39 deaths that occurred between discharge and the 1-year follow-up. The patient disposition is presented in Figure 4, and the baseline characteristics in Table 2 .

The $\mathrm{CV}$ deaths occurred in $0.2 \%$ of patients discharged on prasugrel and in $1.4 \%$ of patients discharged on clopidogrel. The adjusted OR for prasugrel patients compared with clopidogrel patients for CV death was 0.121 (95\% CI 0.026-0.563; Figure 5); for death from any cause OR 0.412 (95\% CI 0.167-1.016); and for presumed CV death OR 0.306 (95\% CI 0.104-0.906).
For patients discharged on ticagrelor, the rates of $\mathrm{CV}$ death, all-cause death, and presumed CV death were $1.3 \%$, $3.8 \%$, and $1.9 \%$, respectively. Patients who were discharged without a $\mathrm{P} 2 \mathrm{Y}_{12}$-inhibitor experienced $\mathrm{CV}$ death in $2.9 \%$, all-cause death in $5.7 \%$, and presumed CV death in $2.9 \%$.

\section{Discussion}

The MULTIPRAC registry was launched in 2011 when many STEMI networks used prehospital DAPT, including clopidogrel, as an established practice in order to provide antiplatelet therapy as soon as possible, as stated in the guidelines. This was done to prepare STEMI patients for primary PCI and this practice was implemented despite a lack of evidence from formal testing. The introduction of newly

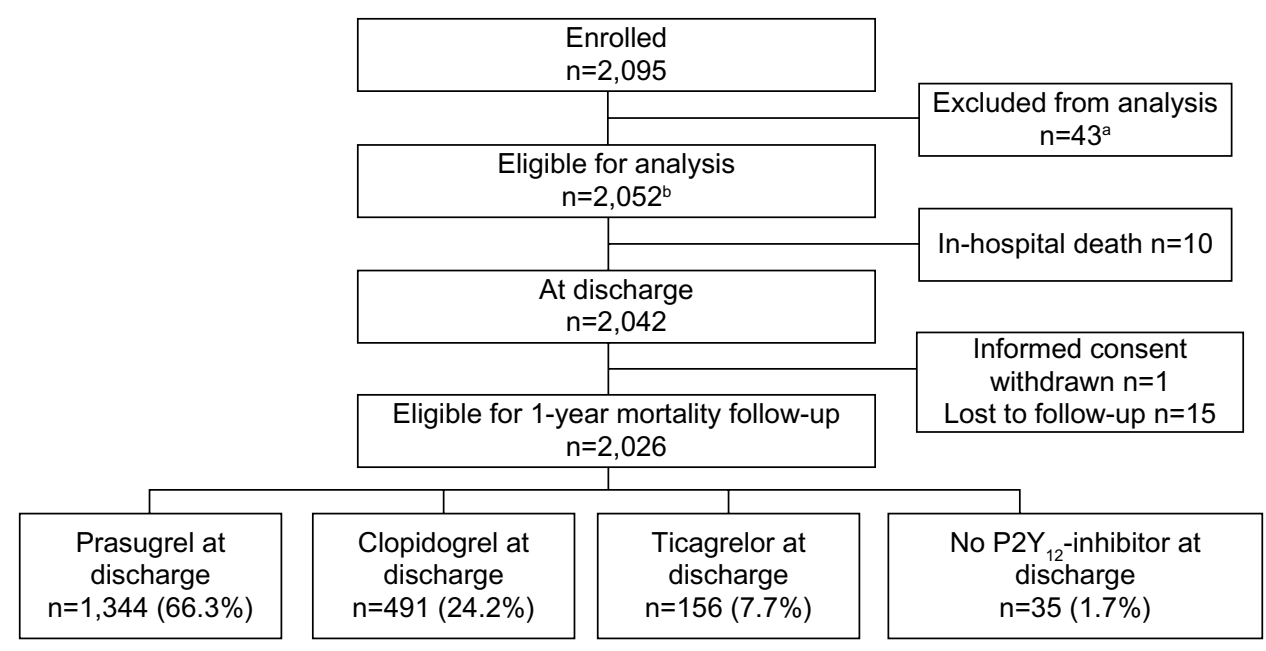

Figure 4 Patient disposition by $\mathrm{P} 2 \mathrm{Y}_{12}$-inhibitor prescribed at hospital discharge.

Notes: ${ }^{a}$ Thirty-one missed loading dose, ten received loading dose in catheterization laboratory, one vomited after loading dose, one had no initial STEMI diagnosis. ${ }^{\text {b Different }}$ from baseline data reported earlier, as one patient needed to be withdrawn (informed consent form was lost).

Abbreviation: STEMI, ST-elevation myocardial infarction. 
Table 2 Baseline characteristics by $\mathrm{P}_{2} \mathrm{Y}_{12}$-inhibitor treatment prescribed at hospital discharge

\begin{tabular}{|c|c|c|c|c|c|}
\hline Characteristic & $\begin{array}{l}\text { All patients, } \\
n=2,026 \\
(100.0 \%)\end{array}$ & $\begin{array}{l}\text { Prasugrel, } \\
\mathrm{n}=1,344 \\
(66.3 \%)\end{array}$ & $\begin{array}{l}\text { Clopidogrel, } \\
n=491 \\
(24.2 \%)\end{array}$ & $\begin{array}{l}\text { Ticagrelor, } \\
n=156 \\
(7.7 \%)\end{array}$ & $\begin{array}{l}\text { P-value, } \\
\text { prasugrel vs } \\
\text { clopidogrel }\end{array}$ \\
\hline Age, years, mean (SD) & $60.8(12.0)$ & $57.5(10.1)$ & $66.5(13.1)$ & $70.2(11.6)$ & $<0.00 \mathrm{I}^{\mathrm{a}}$ \\
\hline Sex, female & $442(21.8)$ & $235(17.5)$ & $158(32.2)$ & $43(27.6)$ & $<0.00 \mathrm{I}^{\mathrm{b}}$ \\
\hline Previous MI & $225(11.1)$ & $130(9.7)$ & $70(14.3)$ & $22(14.1)$ & $0.006^{\mathrm{b}}$ \\
\hline Congestive heart failure & $44(2.2)$ & $22(1.6)$ & $15(3.1)$ & $6(3.8)$ & $0.060^{\mathrm{b}}$ \\
\hline Previous $\mathrm{PCl}$ & $183(9.0)$ & $106(7.9)$ & $56(11.4)$ & $18(11.5)$ & $0.019^{b}$ \\
\hline Previous CABG & $29(1.4)$ & $12(0.9)$ & $12(2.4)$ & $5(3.2)$ & $0.013^{b}$ \\
\hline Previous stroke/TIA & $82(4.0)$ & $14(1.0)$ & $43(8.8)$ & $21(13.5)$ & $<0.00 \mathrm{I}^{\mathrm{b}}$ \\
\hline Peripheral vascular disease & $79(3.9)$ & $31(2.3)$ & $32(6.5)$ & $15(9.6)$ & $<0.00 \mathrm{I}^{\mathrm{b}}$ \\
\hline Chronic renal impairment & $31(1.5)$ & $10(0.7)$ & $16(3.3)$ & $4(2.6)$ & $<0.00 \mathrm{I}^{\mathrm{b}}$ \\
\hline Diabetes mellitus & $27 \mid(13.4)$ & $169(12.6)$ & $76(15.5)$ & $21(13.5)$ & $0.106^{\mathrm{b}}$ \\
\hline Killip class $\geq \mathbb{I I}^{c}$ & $108(7.1)$ & $60(5.9)$ & $33(9.6)$ & II (7.8) & $0.022^{\mathrm{b}}$ \\
\hline $\begin{array}{l}\text { Time from SO to start of } \mathrm{PCl} \text {, } \\
\text { median (hh:mm) }\end{array}$ & $3: 15$ & $3: 07$ & $3: 30$ & $2: 54$ & $0.00 \mathrm{I}^{\mathrm{d}}$ \\
\hline $\begin{array}{l}\text { Time from ISD to start of PCl, } \\
\text { median (hh:mm) }\end{array}$ & $1: 28$ & $\mathrm{I}: 28$ & $\mathrm{I}: 32$ & $1: 23$ & $0.933^{d}$ \\
\hline No of diseased vessels $(\geq 2)$ & $913(45.1)$ & $576(42.9)$ & $248(50.5)$ & $73(46.8)$ & $0.004^{b}$ \\
\hline IRA (LMCA or LAD) & $878(43.3)$ & $584(43.5)$ & $204(4 \mid .5)$ & $72(46.2)$ & $0.467^{\mathrm{b}}$ \\
\hline
\end{tabular}

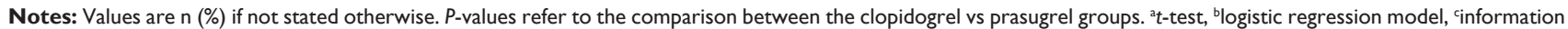
available from I,528 patients, and 'Wilcoxon signed rank test.

Abbreviations: CABG, coronary artery bypass graft; hh:mm, hours:minutes; IRA, infarct-related artery; ISD, initial STEMI diagnosis; LAD, left anterior descending coronary artery; LMCA, left main coronary artery; MI, myocardial infarction; PCI, percutaneous coronary intervention; SD, standard deviation; SO, symptom onset; TIA, transient ischemic attack.

available prasugrel into such strategy, and the associated clinical outcomes for the initial hospitalization have been reported from MULTIPRAC earlier. ${ }^{8}$ We did not find significant differences in the rates of major adverse cardiac and cerebrovascular events when comparing patients treated with clopidogrel or prasugrel (1.6\% vs $2.3 \%$ ), even when adjusting for baseline characteristics. In-hospital CV death rate was below $1 \%$, rendering adjustment for $\mathrm{CV}$ death impossible due to the small number of events. In the present prespecified analysis, including the 1-year follow-up, a 2.1\% absolute difference in $\mathrm{CV}$ mortality emerged, favoring prasugrel over clopidogrel. We focused on long-term mortality because it is a hard endpoint, independent from trial-specific definitions, and is an integral measure of both potential areas of impact

Prasugrel versus clopidogrel
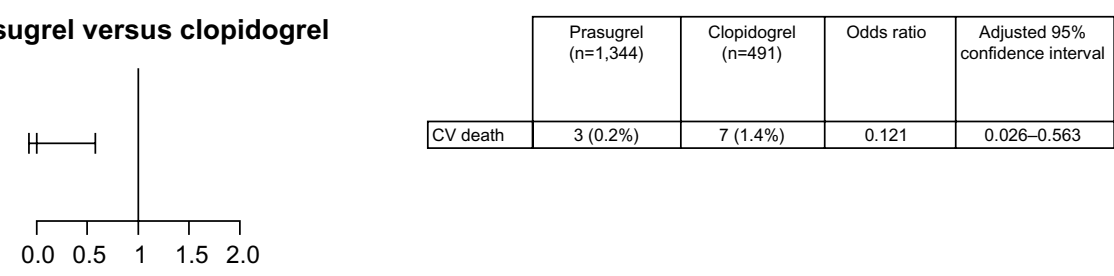

Favors prasugrel Favors clopidogrel

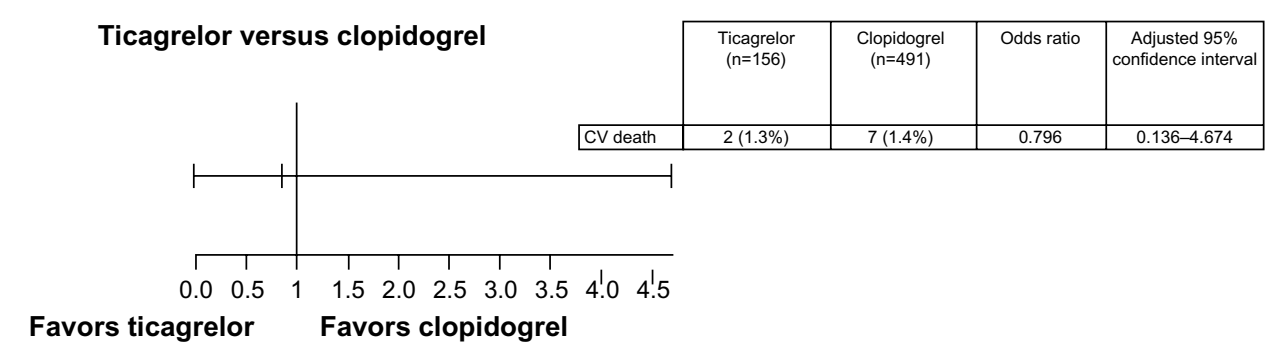

Figure $5 \mathrm{CV}$ death from hospital discharge to I-year follow-up by $\mathrm{P}_{2} \mathrm{Y}_{12}$-inhibitor prescribed at hospital discharge.

Notes: Confidence intervals were adjusted for differences in baseline characteristics. Data are based on linear regression model.

Abbreviation: CV, cardiovascular. 
from antiplatelet medications: reduction in ischemic events and increase in bleeding events (and respective sequelae). Furthermore, when available, looking at CV mortality is preferable, as it excludes other reasons for death that would reduce power when comparing antiplatelet medications.

A similar mortality pattern to that observed in MULTIPRAC - with no significant predischarge difference in mortality but a significant long-term benefit - was previously reported from a single center experience in the UK, ${ }^{9}$ comparing prasugrel and clopidogrel started in-hospital. The 1-year all-cause mortality rate was $4.5 \%$ in the clopidogrel group $(n=822)$ but significantly lower, $2.8 \%$, in the prasugrel group $(n=866)$.

Such a pattern is compatible with the concept that longterm mortality in patients post-STEMI may be a consequence of the initial MI or be attributable to recurrent platelet-mediated ischemic events (new MI, stent thrombosis). One other important contributor to mortality, which is also influenced by antiplatelet medication, is bleeding. ${ }^{10}$ The event rates for re-MI $(0.1 \%$ and $0.2 \%)$ or major bleeding requiring transfusions $(0.5 \%$ and $1.2 \%)$ for the in-hospital phase of MULTIPRAC are low with prasugrel or clopidogrel, respectively. ${ }^{8}$ These differences, though small, would favor a later mortality benefit with prasugrel. To what extent the observed slightly shorter delay from symptom onset to PCI in the prasugrel and switching groups has impacted the observed mortality rates is unclear. Time periods from diagnosis to PCI were similar in all three groups. Additional postdischarge suppression of an accumulation of re-MIs with prasugrel as compared to clopidogrel has been reported previously from the TRITON-TIMI 38 study, ${ }^{11,12}$ while the increased bleeding rate was mitigated when applying label restrictions for use..$^{13}$

Today's in-hospital mortality rate associated with STEMI treated with primary PCI is quite low. Because of this low rate, large samples are required to demonstrate differences between treatments. Therefore, it is interesting that the larger Acute Myocardial Infarction in Switzerland (AMIS Plus) Registry propensity score matched-pairs analysis, including 4,602 patients from Switzerland, found significantly lower in-hospital mortality with prasugrel $(1.8 \%)$ vs clopidogrel (3.1\%). ${ }^{14}$ That study, which included 70\% STEMI patients, did not report adjusted 1-year mortality data.

Similar results have been reported from another, albeit smaller, Swiss registry ${ }^{15}$ reporting both in-hospital and long-term CV mortality for an acute coronary syndrome (ACS) population treated with prasugrel $(\mathrm{n}=756 ; 88 \%$ STEMI) or clopidogrel $(\mathrm{n}=1,392 ; 42 \%$ STEMI). They found a trend toward a lower inhospital ( $0.5 \%$ vs $1.9 \%)$ and 1 -year (2.6\% vs $4.2 \%)$ mortality rate associated with prasugrel compared with clopidogrel.
In an unadjusted analysis from the large Swedish SCAAR registry, the 1,265 STEMI patients treated with prasugrel had a lower 30-day all-cause mortality rate compared with the 5,880 patients treated with clopidogrel (2.5\% vs 5.0\%). ${ }^{16}$ The age difference (with higher age being related to increased mortality) between prasugrel and clopidogrel patients was only 2 years and therefore not the likely cause of the substantial difference in outcomes.

The corresponding RCTs comparing the new $\mathrm{P}_{2} \mathrm{Y}_{12}{ }^{-}$ inhibitors prasugrel or ticagrelor versus clopidogrel are TRITON-TIMI 38 and PLATO. For the respective full ACS study-populations and the composite primary endpoints at study end, both studies reported the newer P2 $\mathrm{Y}_{12}$-inhibitors to be superior to clopidogrel. ${ }^{11,17}$ Data from the primary PCI sub-group $(n=2,340)$ in TRITON-TIMI 38 comparing prasugrel with clopidogrel, where the two $\mathrm{P} 2 \mathrm{Y}_{12}$-inhibitors were started in-hospital, showed a significant absolute 1.3\% reduction in 30-day $\mathrm{CV}$ death rate with prasugrel compared with clopidogrel $(1.2 \%$ vs $2.5 \%, P=0.03) .{ }^{18}$ At 15 -month follow-up, this difference stayed within the same order of magnitude, though it was no longer significant $(P=0.09)$. A previous report from the PLATO study showed that, for a large mixed STEMI population $(\mathrm{n}=7.544)$ including 2,105 patients not treated with primary PCI, there was no difference in early mortality between ticagrelor and clopidogrel. However, there was a trend toward lower $\mathrm{CV}$ mortality at 1 year (difference $1 \%, P=0.07$ ) for ticagrelor versus clopidogrel. ${ }^{19}$ Recently, the outcomes for the primary PCI cohort from PLATO $(n=4,949)$ were disclosed.$^{20}$ In this first reported sub-group from the PLATO study, in which patients were treated with PCI only, similar 1-year CV mortality was reported for ticagrelor and clopidogrel (3.7\% vs $4.0 \%$, $P=0.67)$.

Extending the view beyond STEMI, pretreatment with newer and faster acting oral $\mathrm{P} 2 \mathrm{Y}_{12}$-inhibitors in ACS patients destined for invasive evaluation has recently been challenged in two larger RCTs (ATLANTIC ${ }^{7}$ and $\mathrm{ACCOAST}^{21}$ ). Both failed to show an improvement with pretreatment in terms of standard ischemic endpoints. It could be interpreted that pretreatment is of little importance when 1) the time difference between pretreatment and treatment at the time of PCI is short; 2) there is fast access to PCI; and 3) patients are treated with a potent $\mathrm{P} 2 \mathrm{Y}_{12}$-inhibitor, that is, prasugrel or ticagrelor. In the case of the ATLANTIC study, the results, including no observed difference in bleeding, may be explained by the extremely short duration of pretreatment $(<1$ hour) in the STEMI population studied. In contrast, when the $\mathrm{P} 2 \mathrm{Y}_{12}$-inhibitor 
was applied sufficiently early to establish substantial platelet inhibition at the time of vascular access and PCI, such as in the non-STEMI population studied in ACCOAST, additional bleeding events were observed with pretreatment. However, whereas, clopidogrel was included in the MULTIPRAC registry, it was not included as a comparator in the ATLANTIC and ACCOAST studies. In our real world STEMI population, during the hospital-phase rates of major bleeding were low in all treatment groups. ${ }^{8}$ This deserves particular emphasis, as all our patients started the respective $\mathrm{P} 2 \mathrm{Y}_{12}$-inhibitor prior to reaching the catheterization laboratory, and frequent early switching from clopidogrel to prasugrel with or without a LD was observed.

\section{Limitations}

Due to the difference in the labels of prasugrel and clopidogrel, the groups differed significantly in baseline characteristics. When performing multivariate adjustment for differences in baseline characteristics, potential confounders may not all have been accounted for. The P2 ${ }_{12}$-inhibitors taken after hospital discharge were not monitored, and therefore true long-term exposure to these agents cannot be quantified. However, experience shows that the antiplatelet medication prescribed at discharge is rarely changed in the outpatient setting; it is more often stopped than switched, for example, when bleeding occurs. According to an intentionto-treat approach, for our analyses we assumed that patients continued to take the $\mathrm{P} 2 \mathrm{Y}_{12}$-inhibitor at discharge for the duration of follow-up. Mortality analyses were based on relatively small numbers of deaths. The fact that only patients who could take oral medications prehospital were eligible for enrollment in MULTIPRAC excluded the most severely ill patients, which resulted in a study population at quite low risk of death as compared to fully unselected primary angioplasty populations.

No information on bleeding events following discharge from the initial hospitalization is available.

\section{Summary and conclusion}

In MULTIPRAC, patients from routine practice undergoing primary angioplasty, who were able to start oral antiplatelet therapy prehospital, treatment with prasugrel as compared to clopidogrel was associated with a lower risk of $\mathrm{CV}$ death at 1-year follow-up. This is in line with the results from other registries and the randomized controlled study TRITON-TIMI 38. It supports the preferential recommendation of prasugrel over clopidogrel according to the latest European Society for Cardiology guidelines.

\section{Acknowledgments}

We thank all participating patients and staff, including the doctors and nurses who made this study possible. Further, we are thankful to Josef Schmitt for statistical analyses. Editorial assistance in the preparation of the manuscript was provided by 3P Consulting, Seefeld, Germany, and paid for by Daiichi Sankyo Europe GmbH.

\section{Disclosure}

MULTIPRAC was sponsored by Daiichi-Sankyo Europe GmbH and Eli Lilly and Company. The MULTIPRAC steering committee members, Patrick Goldstein, France (chair), Peter Clemmensen, Denmark (co-chair); Nicolas Danchin, France; Hüseyin Ince, Germany; and Niccolo Grieco, Italy, received study honoraria, travel expenses, or consulting fees from Daiichi-Sankyo and Eli Lilly.

Peter Clemmensen received consulting, speaker fees, and research grants from Abbott, AstraZeneca, Aventis, Bayer, Boehringer Ingelheim, Bristol Myers Squibb, Daiichi Sankyo, Eli-Lilly, Evolva, Fibrex, Janssen, Merck, Myogen, Medtronic, Mitsubishi Pharma, The Medicines Company, Nycomed, Organon, Pfizer, Pharmacia, Regado, Sanofi, Searle, and Servier.

Nicolas Danchin has received research grants from Amgen, Astra-Zeneca, Bayer, Daiichi-Sankyo, Eli-Lilly, GSK, Merck, Novartis, Pfizer, Sanofi-Aventis, Servier, and The Medicines Company and fees for lectures or consulting for Amgen, AstraZeneca, Bayer, Bristol-Myers Squibb, Boehringer-Ingelheim, Daiichi-Sankyo, Eli-Lilly, GlaxoSmithKline, MSD-Schering, Novartis, Novo-Nordisk, Pfizer, Roche, Sanofi-Aventis, Servier, and The Medicines Company.

Yvonne Ramos is an employee of Daiichi-Sankyo Europe $\mathrm{GmbH}$.

Jochen Goedicke is an employee of Lilly Deutschland $\mathrm{GmbH}$. The authors report no other conflicts of interest in this work.

\section{References}

1. Windecker S, Kolh P, Alfonso F et al. 2014 ESC/EACTS Guidelines on myocardial revascularization: The Task Force on Myocardial Revascularization of the European Society of Cardiology (ESC) and the European Association for Cardio-Thoracic Surgery (EACTS). Developed with the special contribution of the European Association of Percutaneous Cardiovascular Interventions (EAPCI). Eur Heart J. 2014;35(37):2541-2619.

2. Heestermans AA, van Werkum JW, Taubert D, et al. Impaired bioavailability of clopidogrel in patients with a ST-segment elevation myocardial infarction. Thromb Res. 2008;122(6):776-781.

3. Alexopoulos D, Xanthopoulou I, Gkizas V, et al. Randomized assessment of ticagrelor versus prasugrel antiplatelet effects in patients with ST-segment-elevation myocardial infarction. Circ Cardiovasc Interv. 2012;5(6):797-804. 
4. Dorler J, Edlinger M, Alber HF, et al. Clopidogrel pre-treatment is associated with reduced in-hospital mortality in primary percutaneous coronary intervention for acute ST-elevation myocardial infarction. Eur Heart J. 2011;32(23):2954-2961.

5. Koul S, Smith JG, Schersten F, James S, Lagerqvist B, Erlinge D. Effect of upstream clopidogrel treatment in patients with ST-segment elevation myocardial infarction undergoing primary percutaneous coronary intervention. Eur Heart J. 2011;32(23):2989-2997.

6. Bellemain-Appaix A, O'Connor SA, Silvain J, et al. Association of clopidogrel pretreatment with mortality, cardiovascular events, and major bleeding among patients undergoing percutaneous coronary intervention: a systematic review and meta-analysis. JAMA. 2012;308(23):2507-2516.

7. Montalescot G, van't Hof AW, Lapostolle F, et al. Prehospital ticagrelor in ST-segment elevation myocardial infarction. $N$ Engl J Med. 2014; 371(11):1016-1027.

8. Clemmensen P, Grieco N, Ince H, et al. MULTInational non-interventional study of patients with ST-segment elevation myocardial infarction treated with PRimary Angioplasty and Concomitant use of upstream antiplatelet therapy with prasugrel or clopidogrel-the European MULTIPRAC Registry. Eur Heart J Acute Cardiovasc Care. 2015;4(3):220-229.

9. Koshy A, Balasubramaniam K, Noman A, Zaman AG. Antiplatelet therapy in patients undergoing primary percutaneous coronary intervention for ST-elevation myocardial infarction: a retrospective observational study of prasugrel and clopidogrel. Cardiovasc Ther. 2014;32(1):1-6.

10. Mehran R, Pocock S, Nikolsky E, et al. Impact of bleeding on mortality after percutaneous coronary intervention results from a patient-level pooled analysis of the REPLACE-2 (randomized evaluation of PCI linking angiomax to reduced clinical events), ACUITY (acute catheterization and urgent intervention triage strategy), and HORIZONS-AMI (harmonizing outcomes with revascularization and stents in acute myocardial infarction) trials. JACC Cardiovasc Interv. 2011;4(6):654-664.

11. Wiviott SD, Braunwald E, McCabe $\mathrm{CH}$, et al. Prasugrel versus clopidogrel in patients with acute coronary syndromes. $N$ Engl J Med. 2007;357(20):2001-2015.

12. Murphy SA, Antman EM, Wiviott SD, et al. Reduction in recurrent cardiovascular events with prasugrel compared with clopidogrel in patients with acute coronary syndromes from the TRITON-TIMI 38 trial. Eur Heart J. 2008;29(20):2473-2479.
13. Wiviott SD, Desai N, Murphy SA, et al. Efficacy and safety of intensive antiplatelet therapy with prasugrel from TRITON-TIMI 38 in a core clinical cohort defined by worldwide regulatory agencies. Am J Cardiol. 2011;1;108(7):905-911.

14. Kurz DJ, Radovanovic D, Seifert B, et al. Comparison of prasugrel and clopidogrel-treated patients with acute coronary syndrome undergoing percutaneous coronary intervention: A propensity score-matched analysis of the Acute Myocardial Infarction in Switzerland (AMIS)-Plus Registry. Eur Heart J Acute Cardiovasc Care. 2016;5(1):13-22.

15. Klingenberg R, Heg D, Raber L, et al. Safety profile of prasugrel and clopidogrel in patients with acute coronary syndromes in Switzerland. Heart. 2015;101(11):854-863.

16. Damman P, Varenhorst C, Koul S, et al. Treatment patterns and outcomes in patients undergoing percutaneous coronary intervention treated with prasugrel or clopidogrel (from the Swedish Coronary Angiography and Angioplasty Registry [SCAAR]). Am J Cardiol. 2014;113(1):64-69.

17. Wallentin L, Becker RC, Budaj A, et al. Ticagrelor versus clopidogrel in patients with acute coronary syndromes. $N$ Engl J Med. 2009; 361(11):1045-1057.

18. Udell JA, Braunwald E, Antman EM, Murphy SA, Montalescot G, Wiviott SD. Prasugrel versus clopidogrel in patients with ST-segment elevation myocardial infarction according to timing of percutaneous coronary intervention: a TRITON-TIMI 38 subgroup analysis (Trial to Assess Improvement in Therapeutic Outcomes by Optimizing Platelet Inhibition with Prasugrel-Thrombolysis In Myocardial Infarction 38). JACC Cardiovasc Interv. 2014;7(6):604-612.

19. Steg PG, James S, Harrington RA, et al. Ticagrelor versus clopidogrel in patients with ST-elevation acute coronary syndromes intended for reperfusion with primary percutaneous coronary intervention: A Platelet Inhibition and Patient Outcomes (PLATO) trial subgroup analysis. Circulation. 2010;122(21):2131-2141.

20. Steg P. First Presentation of the PLATO Primary PCI Subgroup. Lecture presented at: Transcatheter Cardiovascular Therapeutics (TCT) conference. September 12, 2014; Washington DC, USA. Available from: http://www.tctmd.com/show.aspx?id=126403. Accessed March 1, 2016.

21. Montalescot G, Bolognese L, Dudek D, et al. Pretreatment with prasugrel in non-ST-segment elevation acute coronary syndromes. N Engl J Med. 2013;369(11):999-1010.
Vascular Health and Risk Management

\section{Publish your work in this journal}

Vascular Health and Risk Management is an international, peerreviewed journal of therapeutics and risk management, focusing on concise rapid reporting of clinical studies on the processes involved in the maintenance of vascular health; the monitoring, prevention and treatment of vascular disease and its sequelae; and the involvement of

\section{Dovepress}

metabolic disorders, particularly diabetes. This journal is indexed on PubMed Central and MedLine. The manuscript management system is completely online and includes a very quick and fair peer-review system, which is all easy to use. Visit http://www.dovepress.com/ testimonials.php to read real quotes from published authors. 